\title{
Experiments all the Way in Programmatic Design Research
}

\author{
Anne Louise Bang ${ }^{1} \&$ Mette Agger Eriksen², \\ ${ }^{1}$ Design School Kolding, ${ }^{2}$ Malmö University
}

\begin{abstract}
Experiments take various forms, have various purposes, and generate various knowledge; depending on how, when and why they are integrated in a design research study with a programmatic approach. This is what we will argue for throughout this article using examples and experiences from our now finalized PhD studies. Reviewing the prevailing literature on research through design the overall argument is that design experiments play a core role both in conducting the research, in theory construction and in knowledge generation across the different design domains and methodological directions. However, we did not identify sources that explicitly discuss and operationalize roles and characteristics of design experiments in different stages of programmatic design research. The aim of this article is therefore to outline a (tentative) systematic account of roles and characteristics of design experiments. Building upon Schön's definition of experiments in practice we propose adding to the prevailing understanding of experiments in research through design understanding and operationalizing design experiments 1 ) as initiators or drivers framing a research programme, 2) as ways to reflect on and mature the research programme serving as vehicles for theory construction and knowledge generation and finally 3) as a 'designerly' approach to the written knowledge dissemination and clarification of research contributions.
\end{abstract}

\section{INTRODUCTION}

Today it is commonly acknowledged in the design research community that design experiments in various forms such as explorations with mockups, prototypes, scenarios, models, design games, probes, artifacts etc. play a central role for knowledge generation and theory-building in research through design or practice-led design research. In 2006-2007 the Danish Centre for Design Research initiated and funded a series of XLab workshops, which explored how we speak about and do design research through a programmatic approach with experiments at its core. It was a meta-project in the sense that it aimed to further explore, understand and operationalize the dialectics between design experiments and the research program (Binder and Redström 2006; Brandt \& Binder 2007; Redström 2011; Brandt, Redström, Eriksen \& Binder 2011). $X$ Lab was inspired by research programs conducted by institutions such as the Swedish Interactive Institute in the late 1990s and the beginning of the 2000s, for example the IT+textiles program (Redström, Redström \& Mazé 2005). Throughout this article we discuss the role and characteristics of design experiments in different stages of a research programme. We use our experiences as active participants in the XLab workshop series as a frame for the discussion and we exemplify the discussion through examining and reflecting on selected experiments from our finalized $\mathrm{PhD}$ studies.

\section{RESEARCH THROUGH DESIGN, CONSTRUCTIVE DESIGN RESEARCH AND PROGRAMMATIC DESIGN RESEARCH}

Since Frayling (1993) coined the term 'research through art and design', design researchers have been addressing and exemplifying ways in which design examples and practice can contribute to knowledge generation in design research. Recently Koskinen, Zimmerman, Binder, Redström and Wensveen (2011) suggested that it is time to go beyond the notion of research through design. As a result of their research they propose that the research community acknowledges the massive body of work in this field by adopting the term 'constructive design research'. Constructive design research they define as "design research in which construction - be it product, system, space, or media - takes center place and becomes the key means in constructing knowledge" (Koskinen et al. 2011: 5). One main argument in Koskinen et al.'s work is that research programs and larger initiatives developed and rooted within influential design institutions have played a crucial role in maturing the field of constructive design research. Recent 
examples of significant research programs are interaction design in Eindhoven, critical design in London, empathic design and co-design in Scandinavia, service design in Milan and user experience at Carnegie Mellon (Koskinen et al. 2011: 40). Significant for all these 'institutional' programs is that they have design experiments as a core activity for knowledge generation. Also the community at Carnegie Mellon has discussed design research as a 'maturing field' in terms of theoretical contributions within the field. However, they are also mentioning research through design and the interest in design processes as the maybe greatest contribution from the design research community to other research communities (Forlizzi, Zimmerman, \& Stolterman 2009). Interesting for our research, XLab did not only refer to programs at institutional and national levels, but also suggested it at a smaller scale, as we shall discuss throughout this paper. Likewise Löwgren, Larsen and Hobye (2013) recently argued for 'doing programs' as a way of framing for example a doctoral study. We see this article as a contribution to the field of research through design / constructive design research, but we too refer to our work using the phrase 'programmatic design research'.

\section{METHODOLOGICAL DIRECTIONS IN CONSTRUC- TIVE DESIGN RESEARCH}

Koskinen et al. (2011) discuss design research by identifying and labelling the prevailing methodological directions: 'the lab', 'the field' and 'the showroom'. However, this way of understanding and discussing the methodology in design research was initiated already in 2008 (Koskinen, Binder, \& Redström 2008). On the one hand each methodological direction refers to and draws on traditional research traditions; natural sciences, social sciences and art. Acknowledging that design research has matured it can also be argued that the three methodological directions are manifesting as ways of describing methodology and experiments in design research in their own right.

\section{Experiments as vehicles for theory-building}

If we look in the direction of the 'lab' methodology, the research conducted within interaction design by design researchers at the Technical University in Eindhoven plays a significant role. An example is the PhD-work conducted by Frens, who prototyped a camera, which lead to theory development about 'rich interaction'. Frens was a part of a larger research program drawing on ecological psychology (Koskinen et al. 2011: 51-55). The design experiments conducted in the studies within this program typically had the form of prototypes, which served as vehicles for theory development. This is also the case for the research within product design conducted at the ID-StudioLab based at Delft University of Technology. The design experiments conducted within this research program are often prototypes, which are described as carriers of knowledge (Stappers 2007).

Others also discuss the transitioning from or between rich experiment data/insights and knowledge production in design research. Zimmerman and Forlizzi (2008) have for example emphasized the role of design artifacts in theory construction. Based on a review of research projects within these fields they suggest that researchers can take a 'philosophical' or a 'grounded' approach to research through design and in both cases "design researchers make propositions of 'what could/should be' through the construction of artifacts" (ibid: 44). Zimmerman and Forlizzi describe experiments in design research as carriers of knowledge but also as a specific instantiation of a model (theory) that allows the researcher to link current states with preferred states.

\section{Experiments as areas of concerns and judgments} According to Koskinen et al. especially critical design, which origins from the 1990 es Computer-Related Design program at the Royal College of Art in London, has contributed to establish the 'showroom' as a methodological direction in design research. Critical design is inspired by radical design movements and avant-garde art with a dedicated interest in exploring the impact of science on society (Koskinen et al. 2011). Recently Bill Gaver, who was a researcher and interaction designer in that program, has argued that: "an endless string of design examples is precisely at the core of design research" (Gaver 2012: 938). Gaver views one artefact or design example as filling out one point in a design space, while a collection of multiple examples what he calls a 'portfolio' - establish an area or domain of concerns and judgments in the design space (ibid: 944). Gaver further argues that to respect the richness and particularity of the design examples, the role of theory is to annotate these rather than to replace them.

\section{Experiments as 'contextual' knowledge generators}

The methodological direction 'field' draws mostly on research approaches from social sciences. Especially methods from ethnography and anthropology have influenced and inspired this direction of design research. Adopted to design research these approaches are often combined with exploring mockups, prototypes and co-design tools such as design games, workshops and scenarios (Koskinen et al. 
2011: 75-76). One prominent example stems from the design research community at the Finnish Aalto University where researchers worked for years in Rio de Janeiro. The Vila Rosário project aimed to improve public health through design research (Koskinen et al. 2011: 70). Also the DAIM project (Design Anthropology Innovation Model) interplays with the (re)framing of the program and theorizing eventually captured in the manifesto Rehearsing the Future.

Taking the starting point in a pilot project about engaging citizens in waste reduction and recycling the project laid "out a strategic direction for creating design opportunities that evolve around lived experiences" (Halse, Brandt, Clark \& Binder 2010).

The above is a brief account of contemporary and prevailing interests in constructive design research with a specific focus on design experiments. Among the different design domains and methodological directions the overall argument is that design experiments play a core role both in conducting the research, in theory construction and in knowledge generation. This further indicates that design experiments may play different roles dependent on the actual stage of exploring a research program. However, we did not identify sources that explicitly discuss and operationalize roles and characteristics of design experiments throughout a programmatic design research study. We find that there is a need to elaborate this further in the design research community. An increased knowledge about this topic will contribute to the operationalization of design experiments and thereby further strengthen the arguments and knowledge generation in the field. The aim of this article is therefore to outline a (tentative) systematic account of roles and characteristics of design experiments in different stages of a design research study taking a programmatic approach.

\section{DESIGN EXPERIMENTS}

Interesting to this research is, that as early as 1983 Schön described how design practitioners engage in different types of experiments depending on the purpose of experimenting. He observed and argued that experiments in (design) practice are different from experiments in science, and he defined three types of experiments in practice: exploratory, move testing, and hypothesis testing. It is worth to notice that Schön does not use the words 'testing' and 'hypothesis' in a strict scientific sense. An exploratory experiment, he describes, is undertaken only to see what follows in order to get a feel for things and it succeeds when it leads to a discovery. Schön further argues that reflection-in-action happens through understanding the materials of the (design) situation and the 'back-talk' of the moves made. Such back-talk can be probed and simulated by what he calls a 'move testing experiment', which is an action to produce an intended change with an end in mind. It succeeds when the change has happened. Additionally, the third kind of experiment Schön has observed in practice is the 'hypothesis testing experiment', which is a process of elimination that succeeds when it affects an intended discrimination about competing hypotheses. The main point is that each type of experiment has a different purpose and generates different knowledge.

In line with Schön, XLab suggested viewing experiments, not as 'tests' in a scientific sense or as confirmation of the research program, but as unfoldings of the research, either substantiating or challenging the research program (Brandt et al. 2011: 22). We fully agree with Schön and XLab. Therefore we choose to use Schön's classification of experiments as a starting point for our systematic account of design experiments. In addition to that we adapt $X$ Lab's research on program-experiment dialectics as a foundation for understanding a programmatic approach to design research with experiments at the core.

\section{The research program as a frame and a foundation for design experiments}

XLab suggested viewing a research program as establishing a situated 'provisional knowledge regime' (Brandt et al. 2011: 19). Often with a manifesto character, it is stating an attitude and position, capturing core research issues, intentions and approaches. However, the program needs materialization - to move from the 'abstract' to the 'concrete' (ibid: 35 , $37)$, so at the same time it acts as a frame and a foundation for carrying out inquiries of experiments and interventions (ibid: 19).

In the dissection of the dialectic relationship between research program and design experiments, XLab argues: "Of course, there is much to be gained from reflection and analysis upon each experiment we make, but it is in the relation between program and experiments the most important knowledge is gained." (Brandt et al. 2011: 22). In other words, the program sets a frame for the experiments, making them into more than 'undirected explorations', while it at the same time is open for surprises and new insights arising from the experiments (ibid: 35 ). In this way the program often comes first, but still, it is rarely formulated 'top-down'. Rather, the continuous dialectic interplay is central, as the program in many ways appears in and through the experimentations (ibid: 27-29). 
Finally, XLab suggests that underlying research question(s) has a larger scope than the program (Brandt \& Binder 2007). In other words, question(s) refers to a larger reality/knowledge regime than the program - often also addressed by others in the larger research community. It is thus the program and the experiments as a whole that is addressing the underlying research question(s) (Brandt et al. 2011: 23).

\section{THE XLAB WORKING DIAGRAM IS A 'TOOL TO THINK WITH'}

The main argument of XLab was condensed into a working diagram developed to help understand, operationalize, and talk about design research (Figure 1). The original diagram captures the dialectic relationship by positioning the research program between core experiments and a larger (research) question (Figure 1a).

Practically, in terms of how to (start to) engage in a design research study, the arrows in Figure 1a intend to emphasize how a research study may be initiated from 'the outside' through identifying and positioning larger (research) question(s) or from 'the inside' through practical experiments - and always in relation to a research program.

Additionally, Figure 1b captures XLab's understanding of the unfolding of design research as processes of drift (the dotted squares), stabilization, and closure of one program (the P1 square with the $x^{\prime} e s$ in the centre) and drifts between overlapping programs (P1 and P2 squares), which lie in a longterm programmatic approach to experimental design research (Brandt et al. 2011: 34-35).

\section{ADAPTING AND OPERATIONALIZING THE WORK- ING DIAGRAM TO SPECIFIC CONTEXTS}

We find the arguments, vocabulary, and diagrams of the program-experiment dialectics highly relevant in design research. However, the original diagram (Figure 1a) seems to lack the dynamic processes of researching with a research program, showing basically the units that constitute a research program. Therefore we argue that it is necessary to (visually) adapt and operationalize the diagram in relation to the specific research contexts. For other discussions on modifications and adaptions of the diagram to different research contexts and studies see also Bang, Krogh, Ludvigsen and Markussen 2012 and Markussen, Bang, Pedersen, and Knutz 2012.

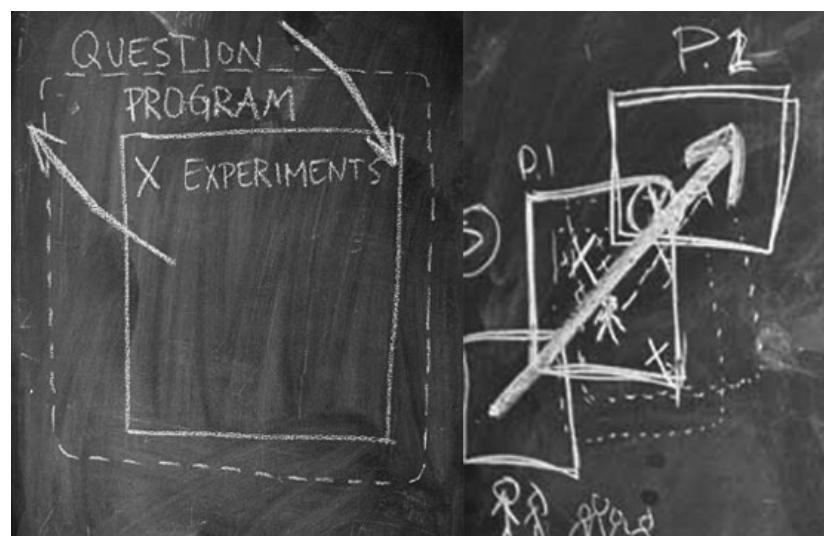

Figure 1 : 1a (left): This figure shows the original XLab working diagram, visualizing the central role design experiments are suggested to take in design research. The arrows emphasize that a research study may be initiated from 'the outside' or from 'the inside'. 1b (right): This figure shows the dynamics of a research program. As new knowledge is gained the 'program' drifts; later come stabilization and closure - leading to the formulation of the next research program (re-print from Brandt et al. 2011: 26, 34).

In the studies we deal with in this article the operationalization manifested as many variations of the diagram closely intertwining with the current content of the research. Figures $2 \mathrm{a}$ and $2 \mathrm{~b}$ below shows two (final) versions of a partly 'dynamic' (and generalized) working diagram. (Figures 5 and 6 are examples of adaptions with content specific to the study).

In line with the original XLab diagram, we fully agree that the program is surrounded by and positioned in 'a wider context'. For both of us the final 'research questions' were continually sharpened and revised throughout the study and thus, they were not formulated until finalizing the PhD theses. Many kinds of questions were asked and formulated, framed, and reframed as questions or statements testing claims. This happened as the studies and arguments dynamically developed along with experiments as well as theoretical and research context positioning.

The diagram in Figure 2a aims to capture the stabilized program between different experiments $(x)$ and exemplars $(X)$ and the larger positioning in relation to theoretical perspectives and related works $(T)$ (Eriksen 2012: 74). The diagram in Figure $2 \mathrm{~b}$ aims to capture the dynamic interplay between research questions and design experiments in relation to the research program $(P)$ framed within an overall challenge (C) (Bang 2010: 50). 

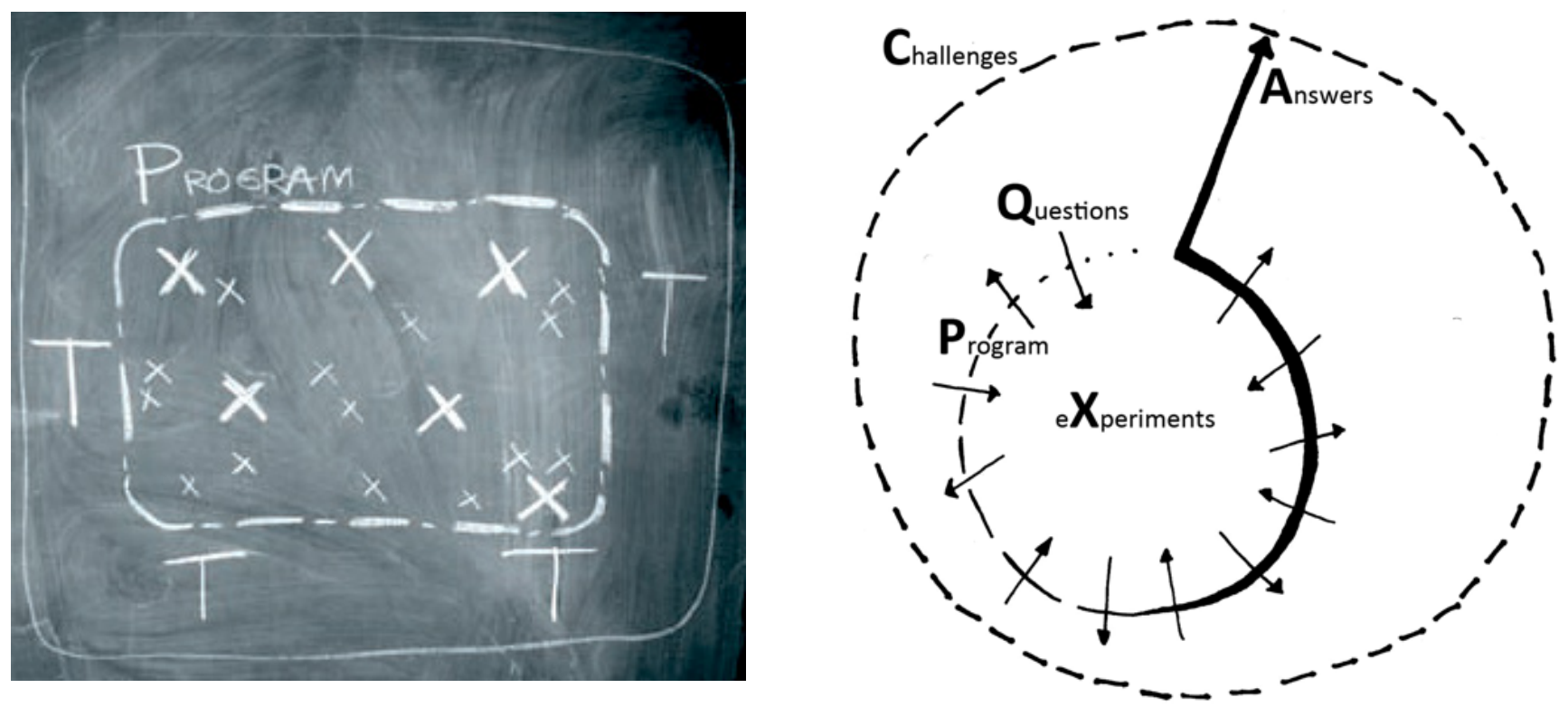

Figure 2 : The figure displays our two previously suggested ways of modifying the original XLab working diagram. 2a (left): This diagram aims to capture the stabilized program between different experiments $(x)$ and exemplars $(X)$ and the larger positioning in relation to theoretical perspectives and related works (T) (reprint from Eriksen 2012: 74). 2b (right): This diagram aims to capture the dynamic interplay between research questions and design experiments in relation to the research program $(P)$ framed within and with the answer (A) as a response to the overall challenges (C) (reprint from Bang 2010: 50).

\section{TOWARDS A (TENTATIVE) SYSTEMATIC ACCOUNT OF DESIGN EXPERIMENTS}

In order to initiate the development of a (tentative) systematic account of design experiments we chose to use our finalized PhD studies to exemplify roles and characteristics of design experiments in different stages of a programmatic design research process. The reason is that we have an in-depth insight in the dynamics of the projects and secondly we have unlimited access to all material. Since we see this as the first step in the development of a systematic account of design experiments we find that it is appropriate to use our own work to exemplify the discussion. However, we are aware that this is by no means exhaustive.

As a starting point for structuring the work we return to the series of the XLab workshops mentioned in the introduction chapter. There were a total of three workshops. The first workshop 'Beginnings' had a focus on how to understand the workshop participants' different projects as program-experiment relations and drifts (Brandt et al. 2011: part 1). The second workshop 'Perform' was concerned with performing and ways in which making an actual experiment can be used to reflect upon what happens in practice (Brandt et al. 2011: part 2). The final 'Intersections' workshop focused on being each other's peers by relating three, at that time, newly defended PhD theses, to understand different ways of making arguments with experiments in design research (Brandt et al. 2011: part 3). We have each chosen three examples from our respective $\mathrm{PhD}$ projects to explore and reflect on roles and characteristics of experiments in the terms of 'beginnings', 'perform' and intersection'. In the discussion we use the examples to step by step argue for the (tentative) systematic account of experiments in design research. We give a brief overview of the two PhD studies in Appendix A on page 4.11.

\section{BEGINNINGS: GET GOING WITH EXPERIMENTS}

In this section we focus on roles and characteristics of previous and early experiments as a part of framing and initiating working with a research program. Example $1 \mathrm{~A}$ and $1 \mathrm{~B}$ in Appendix $\mathrm{B}$ on page 4.12 demonstrate ways in which an experimental approach in the beginning of a study can assist in establishing engagement with the specific research context, research methodology and/or shaping research interests and positions.

\section{Experiments as initiators or drivers framing a re- search program}

As described in example $1 \mathrm{~A}$ as well as example $1 \mathrm{~B}$, the experiments assisted in framing the initial research program. Trained as reflective design practitioners, experienced in working with design programs and briefs, we both found it very fruitful to get going with experiments and reflecting upon these from the beginning of our PhD studies and inquiries. Aiming at a (tentative) systematic account 
of roles and characteristics of experiments in research through design we therefore find it relevant to ask: "What can make experiments in the absolute beginning of a research program so fruitful?"

Documenting the experiments - in both our studies considered as co-design workshops or events generated the 'data', upon which we could reflect and intertwine in the framing of the initial research programs. However, conducting the experiments was not only an empirical data collection. We learned while doing and reflecting on the experiments - either a collection of previous ones or one pre-study experiment. Related to Schön's concept of exploratory experiments, to a large degree these early experiments were conducted to see what followed in order to empathize with the respective study. The experiments played important roles in enabling us to verbally and in text describe our research interests and programmatic positioning. With our respective backgrounds in design practice, only doing this from theoretical points of view would have been challenging, but as the examples show, the experiments enabled us to frame our focuses. For other design researchers this may very well work the other way around - as captured by the arrows in the original XLab diagram (Figure 1a) and also described by Zimmerman and Forlizzi (2008) in terms of choosing a grounded or philosophical approach to design research. followed in order to empathize with the respective study. The experiments played important roles in enabling us to verbally and in text describe our research interests and programmatic positioning. With our respective backgrounds in design practice, only doing this from theoretical points of view would have been challenging, but as the examples show, the experiments enabled us to frame our focuses. For other design researchers this may very well work the other way around - as captured by the arrows in the original XLab diagram (Figure 1a) and also described by Zimmerman and Forlizzi (2008) in terms of choosing a grounded or philosophical approach to design research.

Despite two different starting points, example $1 \mathrm{~A}$ and $1 \mathrm{~B}$ demonstrate that in a specific design research study a program is not generated out of the blue. Rather it emerges from a combination of: i) establishing a research context (where), ii) choosing a research methodology and approach (how) iii) previous and new experiments related to that context (what) and iv) programmatic formulations of interests and challenges - sometimes phrased as questions (why). Thus, we argue that in example $1 \mathrm{~A}$ and $1 \mathrm{~B}$ design experiments basically function as initiators or drivers framing a research program.
PERFORM: SHARPENING THE RESEARCH PROGRAM WITH DESIGN EXPERIMENTS

We use the examples $2 A$ and $2 B$ on page 4.13 to discuss ways in which design experiments contribute to further emphasize performing iterative reflections on actions in the research studies. This is intertwined with re-visualizing and re-formulating diagrams and programs - both as a part of further positioning the research and developing initial knowledge claims.

\section{Design experiments can cause program drift or maturing}

Throughout our respective $\mathrm{PhD}$ studies, engaging in and (co-)organizing the concrete (data-generating) experiments played a central role in performing the studies. We include examples 2A and 2B particularly addressing the iterative performing of experiments.

As described, each of us made many diagram modifications during the research in order to assist the reflective processes of relating the current program with selected concrete (data-generating) experiments. The diagrams in example $2 \mathrm{~A}$ and $2 \mathrm{~B}$ are such modifications that not only captured the development of the research study, but also worked as tools to think with when shaping or understanding the development and dynamics of the research program. Thus, each diagram matches a specific moment in the $\mathrm{PhD}$ studies and expresses actual ideas of the dialectics between the research program and the experiments.

In study A the intension and outcome of the reframing was to stronger position the research and to provoke, challenge, expand, and thus partly drift the program. This programmatic decision closely intertwined with a material methodological shift to onwards stage exploring other corners of the program. In study B the intension was slightly different - to 'fill out' and sharpen the program through the chain or iterations of experiments.

By sketching and naming the dialectics between the research program and collections of experiments, each experiment could be viewed as 'move testing', to use Schön's phrase. For both of us these adapted diagrams became a material, whose back-talk assisted in understanding where we were in our studies and in reframing and formulating themes, focuses, and initial claims. This way of working with the program-experiment dialectics became a process of continually learning with every experiment or a cluster of experiments, as a part of driving the research forward. 
In other words, in both studies the why, what and how of the research programs were continually contested by the experiments and by relating them to the wider research context - often resulting in a reframing of the research and using the diagram modification to explore and understand the program. In both studies such modified diagrams worked as core parts of practically structuring the content and contributions of the thesis. Thus, we argue that design experiments can be used to reflect on and mature the research program serving as vehicles for theory construction and knowledge generation.

\section{INTERSECTIONS: A DESIGNERLY APPROACH TO CLARIFICATION OF RESEARCH CONTRIBUTIONS}

We use examples $3 \mathrm{~A}$ and $3 \mathrm{~B}$ on page 4.14 to show how 'drawing together' in a closing experiment and an iterative 'cut-and-scroll' experiment in the writing process leads to arguments. We discuss the processes of closure as physically drawing our material together, generating knowledge, and making arguments. To us this process meant intersecting our still-at-play research program, selected exemplary experiments, chosen theoretical perspectives, and research contextualization and questions.

\section{From experiments and program to exemplars and arguments - towards closure}

When it was time to write the thesis, we both had a research program that was clearly positioned in relation to the research context as well as a repertoire and collection of experiments and examples that could assist in arguing for the program. In design research, as in other research fields, it is necessary to conduct a systematic analytic inquiry in order to meet academic standards. Yet, when working with the program-experiment dialectics (unfortunately) this is not straightforward since many perspectives and angles could be relevant in the analyses. It surely is a challenging job to choose the 'right' (angle on) experiments, annotate and analyse them with the chosen theoretical perspectives, and turn them into exemplars, which can be offered for critical knowledge dissemination among peers. During analysis and writing processes, it was highly relevant for both of us to ask: "Which examples and/or experiments should be highlighted and turned into exemplars supporting an argument ready for critical knowledge dissemination?" and "How should these exemplars be integrated in the thesis?"

In study A, Eriksen decided to integrate six complementary co-design experiments as exemplars in a special layout, placed in pairs before the three main parts of the thesis. She then refers to and goes into details with these from different angles throughout the text. Additionally, she chose to work with the physical 'landscape' as a part of 'drawing materials and arguments together' in more than words. Taking a different approach, in study B, Bang chose to work physically with the text in parallel with developing and conducting the analyses of the experiments. In the thesis, she chose to present each exemplar in two ways offering both a design tool/framework and a refinement of existing theory. This was a way to emphasise the relevance for design practice and at the same time contribute to theory development in her area of design research.

Using hands-on design skills and 'designerly' ways to analyse the experiments and express the arguments and/or exemplars allowed us to approach the writing process as a 'hypothesis testing' experiment in its own right. Referring to Schön's understanding, 'hypothesis-testing' in this case is understood, as processes of 'elimination' that eventually lead to the final version of the thesis. With this we have identified a third significant way of characterizing design experiments - namely as intertwining in the 'designerly' approach to clarification of research contributions and making the written knowledge dissemination.

\section{ROLES AND CHARACTERISTICS OF EXPERIMENTS IN PROGRAMMATIC DESIGN RESEARCH}

We have used the series of XLab workshops to structure the examples in this article. Thus, 'Beginnings', 'Perform' and 'Intersection' indicate different stages of researching with a research program, namely the initial stages, the iterative 'main research' and the finalizing stages. As a starting point we used Schön's definitions for understanding different types of experiments (exploratory experiments, move testing experiments and hypothesis testing experiments). We have included examples from our finalized $\mathrm{PhD}$ studies to further observe and discuss roles and characteristics of different design experiments in different stages of programmatic design research.

To sum up we identify three different roles and characteristics of design experiments; 1 ) as initiators or drivers framing a research program, 2) as ways to reflect on and mature the research program serving as vehicles for theory construction and knowledge generation and finally 3 ) as a 'designerly' approach to the written knowledge dissemination and clarification of research contributions. In the table below, 
we provide an overview of the (tentative) systematic account of roles and characteristics of design experiments in research through design.

A note on the stages in Table 1: As the text is linear, as with the XLab workshop series, it can appear that we propose a very linear approach of first beginning experiments, then performing experiments and lastly intersecting experiments when working with a programmatic approach to design research. To some extend overall that is the character of working with a design program, but we will encourage not to take this too strictly; because experiments that come to have an initiating or strong framing character still can happen a while into the study or experiments that have the characteristics and role of intersecting can happen for example half way through to thoroughly reflect upon ones positions and current contributions, etc.

\section{A (tentative) systematic account of design experi- ments captured in a diagram}

To conclude the discussion about understanding and operationalizing design experiments in different stages of a programmatic design research, we suggest a new modified diagram (Figure 9). Again, with the aim to summarize the main arguments about experiments all the way in programmatic design research in a 'designerly' way.

As indicated above and throughout the article, we still find Schön's three types of experiments from 1983 suitable and relevant for understanding experiments all the way in programmatic design research, and we fully relate to the roles they capture. However, we also see a need for further discussing the notions of 'testing' and 'hypothesis' in design research. Basically figure 9 merges the diagrams in figure 2, but in addition to these diagrams we differentiate between the three roles and characteristics of experiments, we have identified in this article. We do this by renaming, briefly describing and using the symbols $+,{ }^{*}, x$ and $X$ instead of just the common $x$ for all experiments.

+ 'Initiating or driving experiments': These experiments are driving or initiating experiments intertwining in framing a research program. In this article we draw on XLab and discuss these examples as 'beginnings'. We propose to relate these experiments to Schön's notion of exploratory experiments.

Table 1 : A (tentative) systematic account of roles and characteristics of design experiments in different stages of a research program

\begin{tabular}{|c|c|c|}
\hline $\begin{array}{l}\text { Stages in programmatic design research } \\
\text { (XLab) }\end{array}$ & $\begin{array}{l}\text { Roles of design experiments } \\
\text { (Schön) }\end{array}$ & $\begin{array}{l}\text { Characteristics of design experiments } \\
\text { (Examples in this article) }\end{array}$ \\
\hline Beginnings & Exploratory experiments & $\begin{array}{l}\text { Initiating } \\
\text { Driving } \\
\text { Framing }\end{array}$ \\
\hline Perform & Move testing experiments & $\begin{array}{l}\text { Drift } \\
\text { Reframing } \\
\text { Maturing } \\
\text { Stabilising }\end{array}$ \\
\hline Intersections & Hypothesis-testing experiments & $\begin{array}{l}\text { 'Designerly' ways of drawing together } \\
\text { Making/building theory and knowledge } \\
\text { contributions } \\
\text { Closure } \\
\text { Finalizing }\end{array}$ \\
\hline
\end{tabular}


$X$ and $X$

'Drifting or maturing experiments': These experiments can cause program drift and reframing and they can also assist in maturing and stabilizing the research program. In this article we discuss these experiments in the light of XLab's notion of 'perform'. We propose to relate these experiments to Schön's notion of move testing experiments. Notice that even though we chose not to address this much in the article, intertwining with experiments of reflecting-on-actions, we include the common understanding of (data generating) design experiments $(\mathrm{x})$ and the experiments selected as exemplars $(X)$ as vehicles for theory construction in this category.

* 'Finalizing experiments': These experiments assist in positioning and contextualizing the research program in a 'designerly' way. We use the XLab phrase 'intersection' discussing and characterising these experiments. We propose to relate these experiments to Schön's notion of hypothesis testing experiments.

As in the original XLab diagram (Figure 1a), the performing experiments ( $\mathrm{x}$ and $\mathrm{X}$ ) are placed in different areas of the middle of the diagram, still indicating that design experiments play a core role in programmatic design research. Additionally, we place the driving and initiating experiments $(+)$ and the finalizing experiments $\left({ }^{*}\right)$ on the line that symbolizes the research program, to emphasize that the different roles and characteristics of these experiments also are important to acknowledge in programmatic design research.

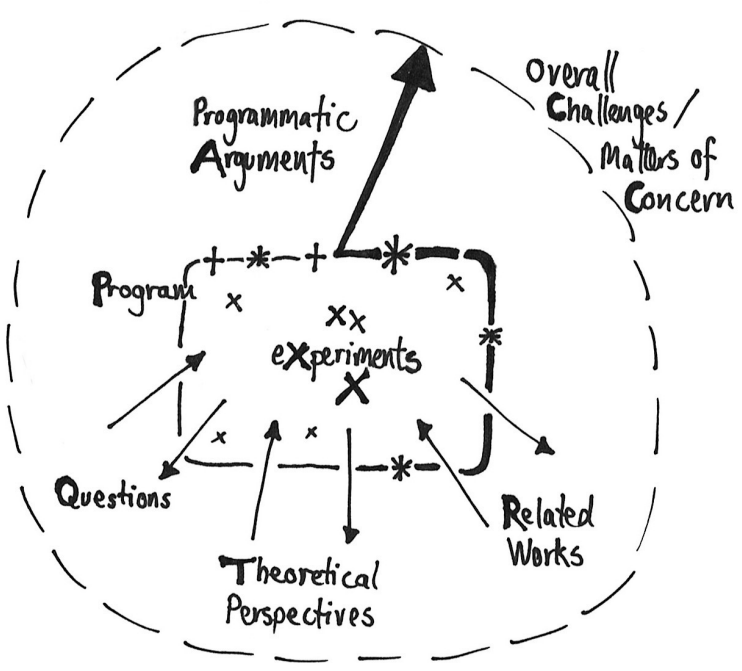

Figure 9: The diagram contains the three roles and characteristics of design experiments that we identify as belonging to the (tentative) systematic account of experiments in programmatic design research. They are marked with the symbols $+,{ }^{*}, \mathrm{x}$, and $X$.

\section{CONCLUDING REMARKS}

As settled in the introduction of this article, it is commonly acknowledged that experiments play a core role in conducting research through design. However, reviewing prevailing literature on the subject we found a need to further understand and discuss this since the roles and characteristics of design experiments was not particularly elaborated and could be further operationalized and understood as a dialectic part of a programmatic approach to design research.

Throughout this article we have exemplified and argued ways in which experiments played important roles all the way through our respective $\mathrm{PhD}$ studies: in the initial stages of beginning to frame the specific research program and contextualize the study; in the middle part where we iteratively were performing experiments intertwined with continual programmatic reflections; and in the closing part of writing the thesis and intersecting experiments and theoretical perspectives by formulating and drawing together contestable exemplars and arguments.

Thus, we conclude the paper by proposing the above (tentative) systematic account of operationalizing design experiments in programmatic design research where we identify and characterize three different roles of design experiments. We are highly aware that this by no means is an exhaustive, full account. Yet with the argument of experiments all the way throughout a design research study with a programmatic approach, we see this article as a contribution to the discussion, understanding and operationalizing of design experiments in programmatic design research, especially in terms of nuancing roles and characteristics of design experiments in different stages of a study.

\section{ACKNOWLEDGEMENTS}

Thanks to Thomas Binder and the Danish Centre for Design Research for initiating and funding the XLab project, to Eva Brandt and Johan Redström and all other XLab workshop participants for fruitful collaborations. Thanks to our PhD supervisors for encouraging us to work with a program-experiment approach, and also thanks to the reviewers and editors for constructive feedback. 


\section{REFERENCES}

Albers, A. (2000). Selected Writings on Design. Middletown, CT: Wesleyan University Press.

Bang, A. (2010). Emotional Value of Applied Textiles - Dialogue-oriented and participatory approaches to textile design. PhD dissertation. Kolding School of Design, Denmark. (Published 2013).

Bang, A., Krogh, P., Ludvigsen, M. \& Markussen, T. (2012). The Role of Hypothesis in Constructive Design Research. Proceedings of The Art of Research Conference IV, Helsinki, 28-29 November 2012.

Binder, T. \& Redström, J. (2006), Exemplary Design Research. Proceedings of Wonderground - The 2006 Design Research Society International Conference, Lisbon, 1-4 November 2006.

Brandt, E., Redström, J., Eriksen, M. \& Binder, T. (2011). XLAB. Copenhagen: The Danish Design School Press.

Brandt, E. \& Binder, T. (2007). Experimental Design Research: Genealogy - Intervention - Argument. IASDR Proceedings. Emerging trends in Design Research. Hong Kong, 12-15 November 2007.

Eriksen, M. A. (2012). Material Matters in Co-designing - Formatting \& Staging with Participating Materials in Co-design Projects, Events \& Situations. PhD dissertation. Malmö University, Sweden.

Forlizzi, J., Zimmerman, J. \& Stolterman, E., (2009). From Design Research to Theory: Evidence of a Maturing Field. Proceedings of International Association of Societies of Design Research Conference, (2009) IASDR Press.

Frayling, C. (1993). Research in Art and Design. Royal College of Art Research Papers 1(1) pp. 1-5.

Gaver, B. (2012). What Should We Expect From Research Through Design? Proceedings of CHI 2012, pp. 937-946. Austin, Texas, May 2012.

Halse, J., Brandt, E., Clark, B. \& Binder, T. (2010). Rehearsing the Future. Copenhagen: The Danish Design School Press.

Koskinen, I., Binder, T. \& Redström, J. (2008). Lab, Field, Gallery, and Beyond. Artifact, 2, p. 46-57.

Koskinen, I., Zimmerman, J., Binder, T., Redström, J. \& Wensveen, S. (eds.) 2011, Design Research Through Practice. Imprint: Morgan Kaufmann.

Latour, B. (2004). Why Has Critique Run out of Steam? From Matters of Fact to Matters of Concern. Critical Inquiry, Vol. 30, No. 2 (Winter, 2004), pp. 225-248. The University of Chicago Press.

Löwgren, J., Larsen, H. \& Hobye, M. (2013) Towards Programmatic Design Research. Designs for Learning, Vol. 6, No. 1-2, p. 80-100.

Markussen, T., Bang, A., Pedersen, P., \& Knutz, E. (2012). Dynamic Research Sketching - A New Explanatory Tool for Understanding Theory Construction in Design Research. Proceedings of 2012 Design Research Society (DRS) International Conference, Bangkok, 1-4 July 2012.

Redström, M., Redström, J. \& Mazé, R. (2005). IT+Textiles. Finland: Edita Publishing, IT Press.
Redström, J. (2011). Some notes on program/experiment dialects. Proceedings of Fourth Nordic Design Research Conference 2011. Helsinki: Aalto University.

Schön, D. (1983). The Reflective Practitioner - How Professionals Think in Action. Basic Books, USA.

Stappers, P. (2007). Doing Design as Part of Doing Research. In: Michel, R. (ed.) 2007. Design Research Now: Essays and Selected Projects, p. 81-91. Basel: Birkhäuser.

Zimmerman, J. \& Forlizzi, J. (2008). The Role of Design Artifacts in Design Theory Construction, p. 41-45. Artifact, 2, 1 (2008).

\section{CORRESPONDENCE}

Anne Louise Bang, Design School Kolding, Aagade 10, 6000 Kolding, Denmark

Email: alb@dskd.dk

Mette Agger Eriksen, Malmö University, Dept. of Arts \& Communication/K3, Östervarvsgatan 11A, Malmö, Sweden

Email: mette.agger@mah.se

Published online 31 December, 2014

ISSN 1749-3463 print/ISSN 1749-3471

DOI: 10.14434 /artifact.v3i2.3976

(C) 2014 Artifact 


STUDY A: Mette Agger Eriksen
PhD program/title: Material Matters in Co-Designing - Formatting
\& Staging with Participating Materials in Co-design Projects,
Events \& Situations (Eriksen 2012).
Duration: PhD start in January 2004 (Studies almost paused 3 x a
year in 2005, 2007, 2010-2011). Thesis defended: June 2012.
Research affiliations and funding: Affiliation: K3 - Malmö Univer-
sity (MAH), Sweden. Four years funding plus one year teaching.
Also affiliated to the Danish Designschool in Copenhagen. Vari-
ous institutions and research projects financed the study.

Background: An architect, specialized in industrial and user-centred communication design. Three years as a research assistant in two EU-funded multidisciplinary, participatory design 'disappearing computer' projects.

Research methodology and approaches: Practice-based research; research through design; interventionistic, participatory design (PD)/co-design (overlaps with action research); programmatic-experimental research.

Research objective: Across several multidisciplinary co-design projects, the study explored and examined roles of various materials in quite explicitly staged situations of co-designing. The objective was to contribute with materiality perspectives as ways of understanding and staging co-designing practices.

Research context. During the study, Eriksen engaged in and drew experiments from five different co-design research projects: WorkSpace, Atelier, PalCom, XLab and DAIM. Experiments here were 'co-design events'/ workshops.

Aims /contributions: Positioning of co-designing as a different practice than designing. / Communicating experiments as 'Exemplars' showing ways of (not) staging co-designing. / Arguing for a broad understanding of 'participating' materials in the situated co-design situation, event and project. / Application of performative perspectives for understanding co-designing processes. / Drawing together arguments and concerns in a 'landscape' and series of challenges for the further development of the co-design field and practices.
STUDY B: Anne Louise Bang

PhD program/title: Emotional Value of Applied Textiles - Dialogue-oriented and participatory approaches to textile design (Bang 2010).

Duration: PhD start: January 2007. Thesis defended: May 2011.

Research affiliations and funding: Affiliation: Design School Kolding, Denmark. Three years funding including one semester teaching and knowledge dissemination. The study was an Industrial PhD, meaning that it was partly funded by the Danish Industrial $\mathrm{PhD}$ program and partly by a company in the Danish textile industry - the main collaboration partner.

Background: A textile designer, specialized in weaving. 12 years experience from practice and teaching before entering the PhD-studies.

Research methodology and approach: Practice-based research; research through design; co-design; a programmatic approach with design experiments at the core.

Research objective: The study examined and explored emotional value of applied textiles. The objective was to operationalize the strategic term 'emotional value' as it relates to applied textiles. The procedure included development of user- and stakeholder-centred approaches, valuable for the industrial textile designer in the design process.

Research context. During the study, Bang had the opportunity to develop tools and frameworks in close collaboration with the design unit at the collaborating company, and with students at Design School Kolding teaching mainly design processes in textile design. Tools and frameworks were developed as experiments in the form of 'co-design events'/ workshops.

Aims/contributions: Creating a frame of reference for the textile design process and a systematic approach to applied textiles. / Understanding and exploring emotional value related to design of applied textiles. / Developing tools for dialogue about the emotional value of applied textiles. / Developing a procedure that invites participation in the design process from users and stakeholders. 


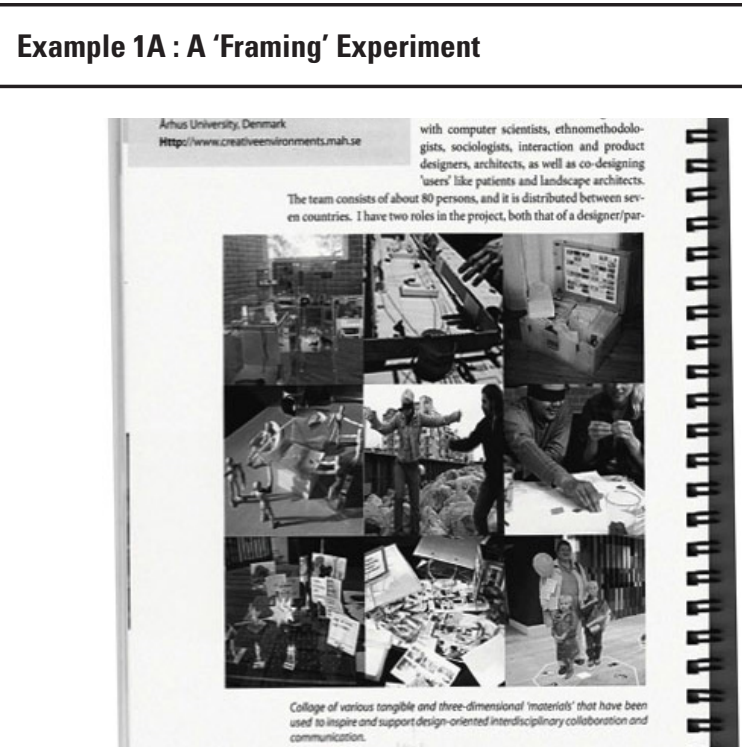

Figure 3 : The initial tentative program framed with a collection of previous experiments in the form of a published 2-page 'researcher's statement'.

Prior to Eriksen's PhD studies, she was a research assistant for three years engaging in two Scandinavian participatory design (PD) research environments, two multidisciplinary EU-funded 'disappearing computer' projects, and other co-design workshop series. From these various engagements she brought a PD approach and a quite extensive collection of smaller and larger co-design workshops/experiments involving tangible materials as well as several co-authored publications about some of these experiences/experiments.

In the beginning of the studies, Eriksen was invited to make a 'research statement' in a publication about the research of her department. This initiated a reflective 'framing' experiment, which involved writing, rewriting, revisiting, relating and reflecting on the previous experiments, including choosing some experiments condensed into a 'collage' of nine images (Figure 3), which visually captured her interests and puzzles. After many revisions, the statement contributed to state the tentative PhD project title as: 'Materially Grounding Imagination - ways of supporting intense interdisciplinary designwork'. All together, this became her initial tentative research program overall capturing how, where and what to focus on in the further research.

This program was shaped in parallel with starting to participate in the PD \& IT research project, PalCom. It assisted in framing the engagement intertwining with further refining the research program - in terms of co-organizing complex cross-partner and stakeholders workshops and processes, and in what to keep an eye for in the documentation of the series of new co-design events/experiments.
Example 1B : An 'Initiating' Experiment
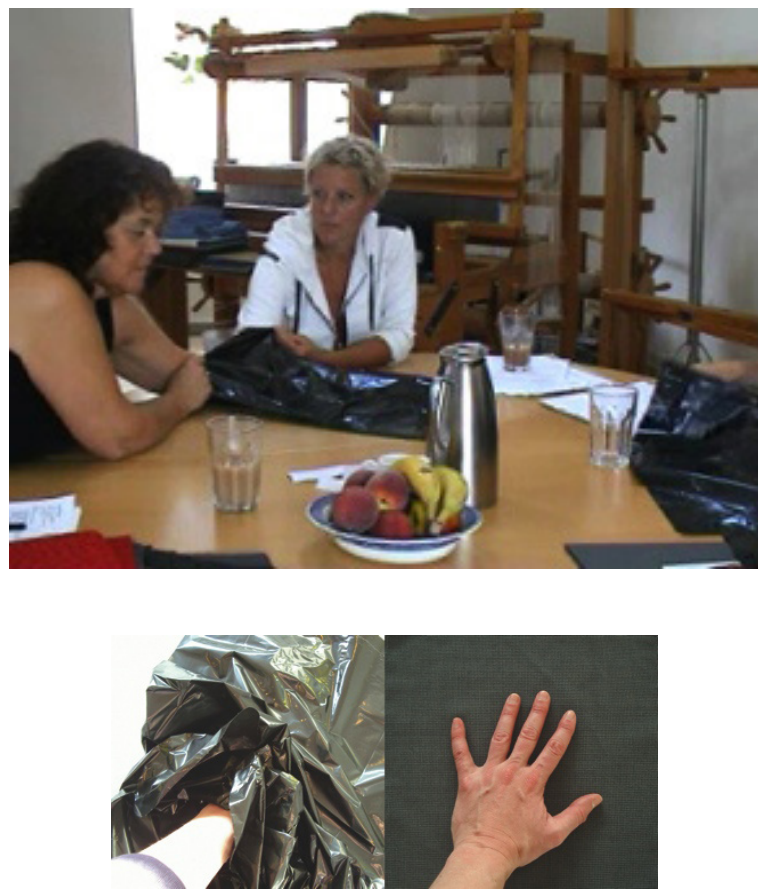

Figure 4 : In the "Fabric-as-Upholstery-Workshop" the Repertory Grid technique was explored as a tool for dialogue.

The first experiment that had a significant influence in Bang's research was conducted in the pre-doc period developing the research in collaboration with the partner company. It was decided to conduct a pilot experiment in order to experience (instead of just talking about) ways in which an experimental approach could be an advantage for the project. This also contributed to strengthening the collaborating partner's engagement in the research.

In the pilot experiment, it was explored whether a variation of the Repertory Grid (interview technique from psychology) could support the dialogue about sensory perception of fabrics and other flexible materials, which in this case were examined as if they were upholstered.

Over time the pilot experiment turned out to have a significant influence on the subsequent experiments in the $\mathrm{PhD}$ study. Firstly, the Repertory Grid was continually explored and refined through the study as a tool for dialogue in design practice/design research. It was a way to structure a dialogue about soft and immeasurable concepts such as emotional value in relation to applied textiles. Secondly, the experiment caused a reframing of the emerging research program from a narrow focus on tactility to a broader focus on emotional value.

Thus, the pilot experiment heavily contributed to the first tentative objective and formulation of the research program. It also laid out the ground for experimentation, 'suggesting' ways in which the next experiment could be formed and conducted. It became the 'mother' of a series of iterative experiments in the study. 


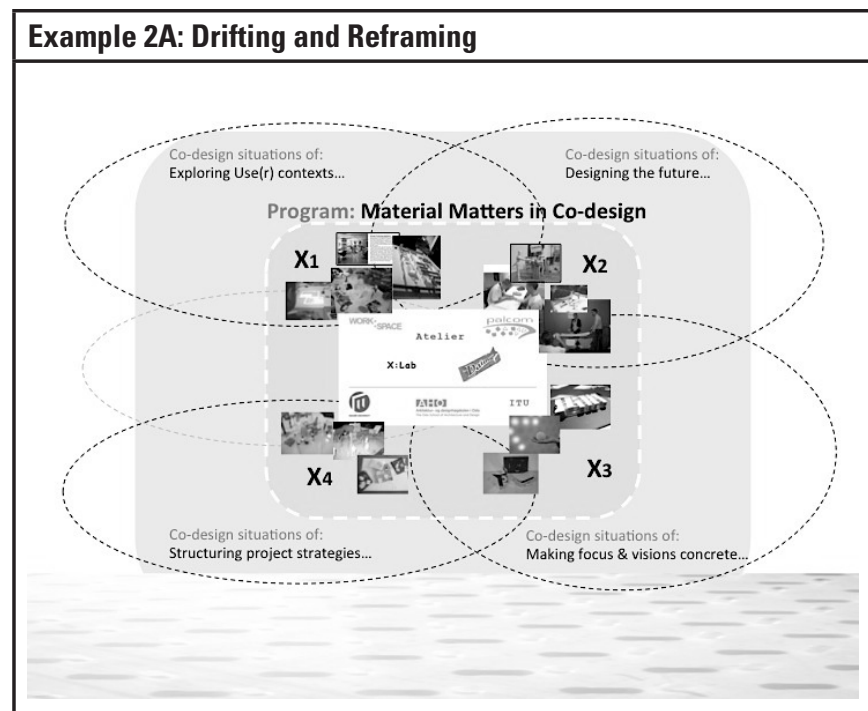

Figure 5: This diagram was one version of naming different clusters of experiments (X1-X4) across the co-design projects in Eriksen's study. It was challenging the program, and pushed her to expand and reframe it.

About two years into the studies (in 2006), Eriksen's program drifted. The title of her program changed from the initial 'Materially Grounding Imagination' to 'Material Means', and soon thereafter again renamed to 'Material Matters', which developed and stabilized as the final research program.

Intertwining with this, Eriksen was mapping and reflecting on the entire collection of experiments, and for example saw many experiments exemplifying co-designers working with various forms of mock-ups, prototypes and scenarios as useful ways of 'designing the future' - surely fruitful practices of engaging tangible materials in multidisciplinary co-designing. However, relating this to the large body of PD literature about such practices, it was clear that this was theoretically well recognized and that many others were researching this topic too. There was a need of making a programmatic decision. Either, the focus could be narrowed down to a detailed study of those materials in co-design situations, or she could aim also for other experiments addressing different materials and focuses of co-design situations, events, and projects. She chose the last drift.

This decision and program reframing was affecting the specific staging of coming co-design experiments. Practically (and interventionistically) it pushed her to co-organize co-design situations in which materials were engaged for other purposes than prototyping etc. - e.g. during the XLab project. Theoretically, this move also pushed Eriksen to explore broader perspectives of how materials are participating and performing in co-designing, which became the main focus and research contributions.
Example 2B: Maturing and Stabilizing

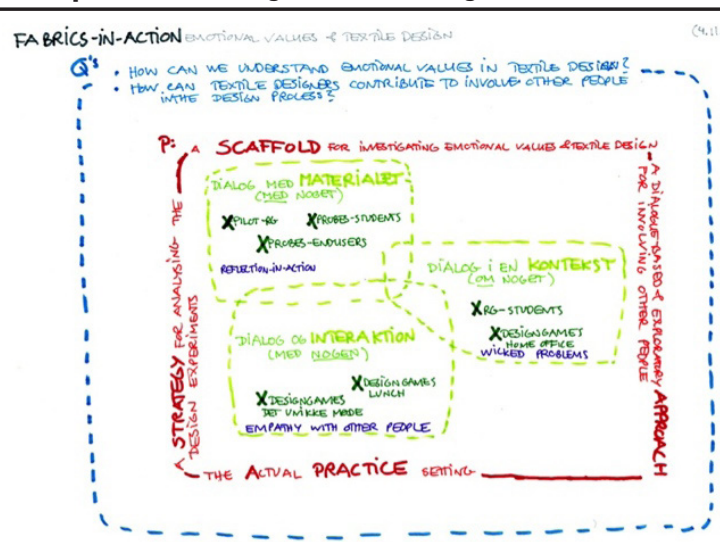

Figure 6: This diagram captures a late stage in Bang's study. The experiments are tentatively organized in groups as a part of maturing the research program and structuring the content of the thesis.

Throughout Bang's research, each design experiment challenged and substantiated the research program in various ways. It was challenged in the sense that each experiment revealed knowledge gaps in the research, and it was substantiated in the sense that each experiment added to the knowledge generation. Thus, the experiments were conducted in an iterative process, with each new design experiment building on the previous one. Reflecting upon each experiment, three main themes emerged and dominated the iterations.

One major theme was the study of emotional value in relation to applied textiles. During the experiments, focus on textiles changed from a narrow focus on 'textiles as material' to a broader focus on 'textiles as part of an object in a context'. This change in focus influenced the choice of materials in the experiments. Another major theme was the dialogue about emotional value. As it happened, each experiment throughout the project explored a modified version of the Repertory Grid as a tool for dialogue and thereby refined the use of the technique in the field of textile design. The third major theme was participation. One of the objectives with the project was to explore ways in which different stakeholders from the collaborating company could participate/contribute to the design process. Different participatory approaches were tried out during experiments, and eventually it was decided to continue with design games and therefore the final experiments tried to refine an appropriate procedure.

Thus, by mapping the different experiments and themes Bang's program was being 'filled out'. 


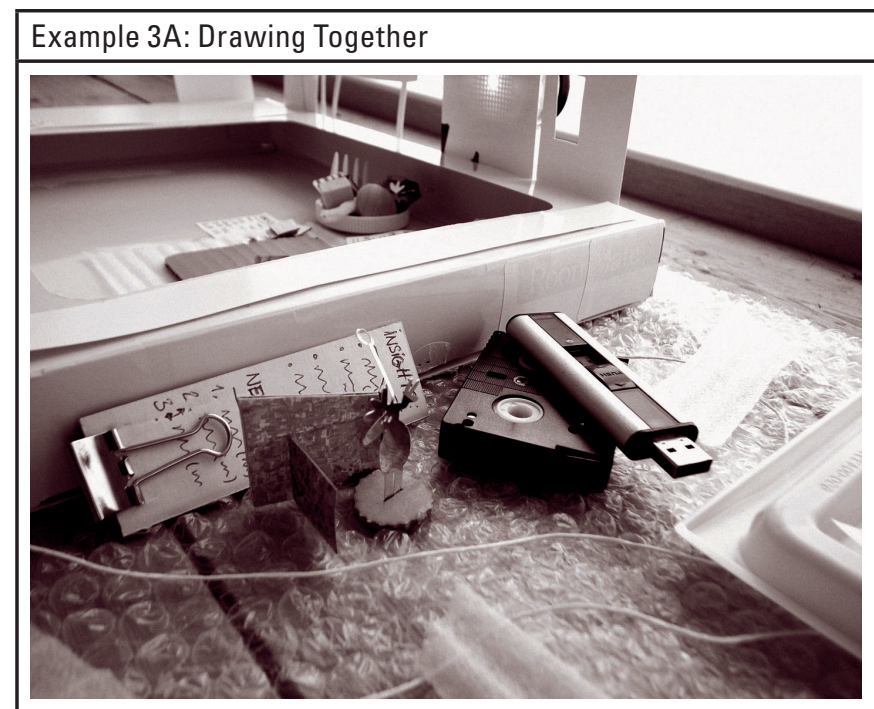

Figure 7: 'Material Landscape of Co-designing' drawing different insights, concerns, and arguments together in a catalogue (image = no. $\mathrm{H}$ 'Co-design Event Aftermath' / copied from Eriksen 2012: 352).

While writing the PhD thesis, Eriksen chose six co-design events/experiments from the collection and made these into rich visual and narrative accounts of what had happened (Eriksen 2012/Exemplars 01-06). Placed in pairs throughout the thesis drafts, these were intertwining in the discussions and arguments of the three main emerging parts - each with different theoretical perspectives and angles. Yet, concurrently, inspired by Latour (e.g. 2004), Eriksen worked on how to further 'draw together' the programmatic arguments in a 'designerly way'.

Eventually, in the latter analytical process a final experiment was conducted. With various tangible materials, a three-dimensional so called catalogue 'landscape' was built. With a camera, details in the landscape were captured highlighting certain arguments. In the computer these were merged with different styles of texts. Often the image was not quite capturing the intended point, which caused another iteration of the landscape. What Eriksen physically made and 'rematerialized' was a tangible but abstracted 'landscape' in which both her understanding of and proposed staging of (future) co-designing were drawn together. In the thesis, this catalogue ended up being a core part of the concluding chapters.

The research program and thesis title, Material Matters of $\mathrm{Co}_{0}$ designing, did not change for years, but its detailed programmatic statements still developed while writing the thesis. Making the physical 'landscape' assisted in finally stabilizing and closing the arguments, program and thesis (Eriksen 2012).
Example 3B: Cut-and-scroll

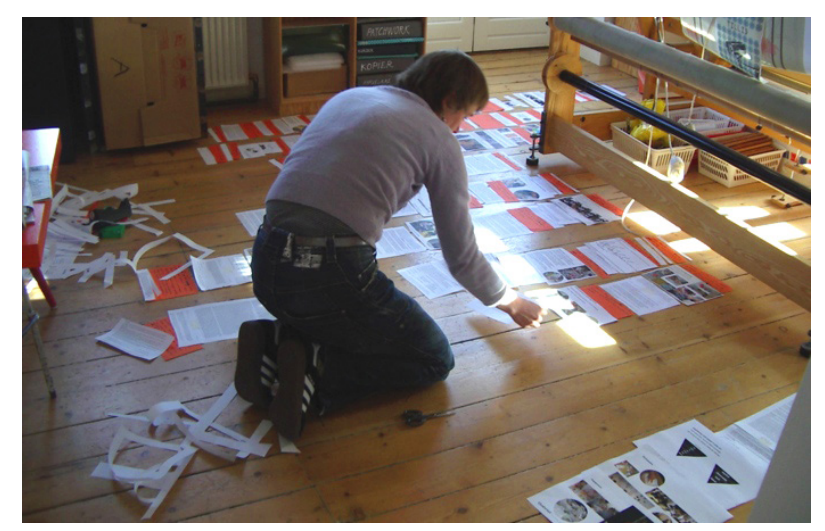

Figure 8: Writing up in a 'designerly' and practice-oriented way. The darker paper snippets pose questions that are answered by the following bits of text and images representing analysis and experiments.

While organising and analysing the material for the thesis, Bang realised that she needed an approach, which allowed her to use design skills in the writing process. Inspiration was found in the work of Bauhaus designer, Anni Albers, who made scrolls when she wrote her essays in order to create an overview of the text, securing flow and continuity. (Albers 2000: vii). Inspired by this Bang physically worked with the text by cutting it in pieces and combining these pieces with questions and images from various presentations and experiments. After that, it was revised and rewritten on the computer.

The cut-and-scroll process was repeated numerous times, which resulted in step-by-step building and physically making the thesis.

The 'cut-and-scroll' work was conducted in parallel with the final analyses of the experiments. It assisted in the final selection and combination of experiments for the thesis. It was also a means for extracting the arguments/exemplars and making decisions for the final structure of the thesis. In the end, this way of approaching the writing-up and analysis processes enabled Bang to extract four main themes - each theme consisting of an argument and a tool/framework.

The four themes, which express the core of the 'Answers' to the research program, Emotional value of applied textiles, are centred on 1) the textile design process and applied textiles, 2) understanding and exploring emotional value in relation to design of applied textiles, 3 ) the rules and procedures of a Repertory Grid as tools for dialogue among a group of participants and 4) stakeholders' participation structured as design games (Bang 2010: 246). 